\title{
Prospective randomized study comparing clinical, functional, and aesthetic results of minipterional and classic pterional craniotomies
}

\author{
Leonardo C. Welling, MD, PhD, ${ }^{1}$ Eberval G. Figueiredo, MD, $\mathrm{PhD},{ }^{2}$ Hung T. Wen, $\mathrm{PhD},{ }^{2}$ \\ Marcos Q. T. Gomes, MD, ${ }^{2}$ Edson Bor-Seng-Shu, MD, PhD, ${ }^{2}$ Cesar Casarolli, MD, ${ }^{2}$ \\ Vinicius M. P. Guirado, MD, ${ }^{2}$ and Manoel Jacobsen Teixeira, MD, PhD² \\ 'Department of Neurosurgery, ${ }^{2}$ University of São Paulo, Brazil
}

\begin{abstract}
OBJECT The object of this study was to compare the clinical, functional, and aesthetic results of 2 surgical techniques, pterional (PT) and minipterional (MPT) craniotomies, for microsurgical clipping of anterior circulation aneurysms.

METHODS Fifty-eight patients with ruptured and unruptured anterior circulation aneurysms were enrolled into a prospective randomized study. The first group included 28 patients who underwent the MPT technique, and the second group comprised 30 patients who underwent the classic PT craniotomy. To evaluate the aesthetic effects, patients were asked to grade on a rule from 0 to 100 the best and the worst aesthetic result. Photographs were also taken, assessed by 2 independent observers, and classified as showing excellent, good, regular, or poor aesthetic results. Furthermore, quantitative radiological assessment (percentage reduction in thickness and volumetric analysis) of the temporal muscle, subcutaneous tissue, and skin was performed. Functional outcomes were compared using the modified Rankin Scale (mRS). Frontal facial palsy, postoperative hemorrhage, cerebrospinal fistula, hydrocephalus, and mortality were also analyzed.
\end{abstract}

RESULTS Demographic and preoperative characteristics were similar in both groups. Satisfaction in terms of aesthetic result was observed in 19 patients $(79 \%)$ in the MPT group and $13(52 \%)$ in the PT group $(p=0.07)$. The mean score on the aesthetic rule was 27 in the MPT group and 45.8 in the PT group $(p=0.03)$. Two independent observers analyzed the patient photos, and the kappa coefficient for the aesthetic results was 0.73 . According to these observers, excellent and good results were seen in 21 patients (87\%) in the MPT and $12(48 \%)$ in the PT groups. The degree of temporal muscle, subcutaneous tissue, and skin atrophy was $14.9 \%$ in the MPT group and $24.3 \%$ in the PT group $(p=0.01)$. Measurements of the temporal muscle revealed $12.7 \%$ atrophy in the MPT group and $22 \%$ atrophy in the PT group ( $p$ $=0.005$ ). The volumetric reduction was $14.6 \%$ in the MPT and $24.5 \%$ in the PT groups $(p=0.012)$. Mortality and mRS score were similar in both groups at the 6 -month evaluation $(p=0.99)$.

CONCLUSIONS Minipterional craniotomy provides clinical results similar to those of the PT technique. Moreover, it provides better cosmetic results. It can be used safely and effectively to surgically treat aneurysms of the anterior circulation instead of the PT approach.

Clinical trial registration no.: NCT01872741 (clinicaltrials.gov)

http://thejns.org/doi/abs/10.3171/2014.11.JNS146

KEY WORDS craniotomy; intracerebral aneurysms; atrophy; temporal muscle; outcome; diagnostic and operative techniques

$\mathrm{T}$ HE primary goal of intracranial aneurysm treatment is complete, permanent, and safe aneurysm occlusion while maintaining flow in the vessels associated with the aneurysm. Aneurysms are very diverse; therefore, the surgical approach depends in large part on the specific aneurysm to be treated, its relationship to the skull, the surrounding structures, and morphology. In this context, the pterional (PT), or frontotemporosphenoidal, approach is one of the most commonly used in vascular neurosurgery. ${ }^{1,2,6,12,26-28}$

ABBREVIATIONS MPT = minipterional; $\mathrm{mRS}=$ modified Rankin Scale; $\mathrm{PT}=$ pterional; $\mathrm{ROI}=$ region of interest.

SUBMITTED January 5, 2014. ACCEPTED November 4, 2014.

INCLUDE WHEN CITING Published online December 19, 2014; DOI: 10.3171/2014.11.JNS146.

DISCLOSURE The authors report no conflict of interest concerning the materials or methods used in this study or the findings specified in this paper. 
Temporal muscle atrophy is a frequently encountered complication plaguing neurosurgeons after successful PT craniotomies. The temporal muscle can sustain injury leading to atrophy by denervation of the muscle, damage to its vascular supply, or direct muscle fiber injury.,10,11 Advances in neurosurgical techniques and instrumentation have led to great improvement in surgical outcomes in patients; however, considerable attention must be paid to the cosmetic results of modern neurosurgery. ${ }^{9}, 16$

Several different techniques have been proposed to reduce the size of the PT craniotomy and its related complications; however, they have failed to provide comparable microsurgical exposure, and some do not reduce the extent of temporal muscle dissection. ${ }^{5,14,22}$ In this context, alternative approaches, such as the minipterional (MPT) craniotomy, have been proposed to overcome these drawbacks. ${ }^{10,11}$

There is debate regarding the effectiveness of the MPT technique and its outcome, including its peculiar risks. ${ }^{10,11,16}$ The main arguments against limited craniotomies are restricted maneuverability and narrowing of the visual field. These conditions could theoretically contribute to worse clinical results in aneurysm surgery via minimally invasive craniotomies..$^{10,11,16,18}$

The surgical literature has very few studies comparing operative techniques. Surgeon preference and experience, rather than well-designed prospective randomized studies, usually dictate the selection of approaches. Thus far, to our knowledge, no studies reported in the literature have directly compared the clinical and cosmetic results of these 2 techniques. We present a prospective randomized study comparing the clinical, functional, and aesthetic results of the classic PT and the MPT craniotomies.

\section{Methods}

\section{Patient Population}

Between October 2010 and July 2012, a total of 58 patients with anterior intracranial aneurysms underwent surgery in the Department of Neurosurgery, University of São Paulo, Brazil. The patients consisted of 18 males and 40 females, their ages ranging from 25 to 79 years (mean 50.7 years). Forty procedures followed an acute subarachnoid hemorrhage, and 18 operations were performed in patients with unruptured aneurysms. The patients were randomly allocated between 2 groups just before the surgery. Twenty-eight patients were treated with the MPT technique, and 30 underwent the classic PT craniotomy. Patients with intracranial hematomas, ophthalmic artery aneurysms, and giant aneurysms were excluded from the study.

The procedures were randomly performed by the same groups of surgeons.

Hospital ethics committee approval was given for the study, and informed consent was obtained from the patients or their relatives. This study was registered with the ClinicalTrials.gov database (http://clinicaltrials.gov), and its registration no. is NCT01872741.

\section{Surgical Technique}

Pterional craniotomy was performed as described by
Yaşargil and Fox..$^{28}$ The MPT technique was performed as described by Figueiredo et al. ${ }^{11}$ and is detailed as follows.

The patient is positioned supine with the head elevated $10^{\circ}-15^{\circ}$ degrees to ensure that the final position of the head is above the level of the heart. The neck is maximally extended to increase the contribution of gravity and venous drainage. The degree of head rotation varies according to the aneurysm location.

An arcuate scalp incision is begun $1 \mathrm{~cm}$ above the base of the zygomatic arch at the anterior border of the hairline. It is extended cranially and curved gradually toward the ipsilateral midpupillary line (Fig. 1 left). Next, a classic interfascial dissection is performed, and the muscular flap is retracted caudally and posteriorly, subperiosteally. At this point, the pterion is completely exposed (Fig. 1 right). Figure 2 illustrates the skin incisions of the 2 craniotomies.

A high-speed drill is used to remove the bone and create the osteotomies. The bur hole is placed under the temporal line, just superior to the frontozygomatic suture. The osteotomy is placed under the superior temporal line, and when it reaches the stephanion, it curves downward to include the pterion within the bone flap. The dura mater is separated from the inner aspect of the skull. The flap includes a minimal portion of the temporal and frontal bones. As described in the classic PT craniotomy, the sphenoid ridge is drilled until emergence of the meningoorbital artery at the superior orbital fissure. The entire area of the craniotomy is under the temporal muscle (Fig. 3). Figure 4 shows a comparison of the bone flaps of the 2 craniotomies. In the PT technique, the area of craniotomy is beyond the temporal muscle limits and requires extensive muscle dissection and retraction.

The dura is opened in a semilunar fashion with its base directed toward the sphenoid wing. The exposed structures include the inferior frontal gyrus, sylvian fissure (with the anterior sylvian point), and the superior temporal gyrus. This approach permits access to the bilateral opticocarotid, interhemispheric, chiasmatic, and ipsilateral crural cisterns as well as the proximal portion of the contralateral sylvian fissure.

\section{Follow-Up}

Postoperatively, CT scans were routinely performed within the first 48 hours. After discharge, patients were followed up on an outpatient basis at 3 and 6 months after surgery. Clinical outcome, aesthetic evaluation, radiological data (including temporal volume analysis; thickness of the temporal muscle; and thickness of the temporal muscle, subcutaneous tissue, and skin), surgical management, approach-related complications, and the postoperative course were recorded.

\section{Clinical Outcomes}

The clinical and functional outcomes were assessed in all patients after surgery. The modified Rankin Scale (mRS) was used to assess functional outcome. Scores of 0 and 1 were considered as an excellent result, 2 and 3 as good, and 4 and 5 as bad. The mRS score was determined at discharge from the hospital and on an outpatient basis at 3 and 6 months after surgery. Other medical variables, 

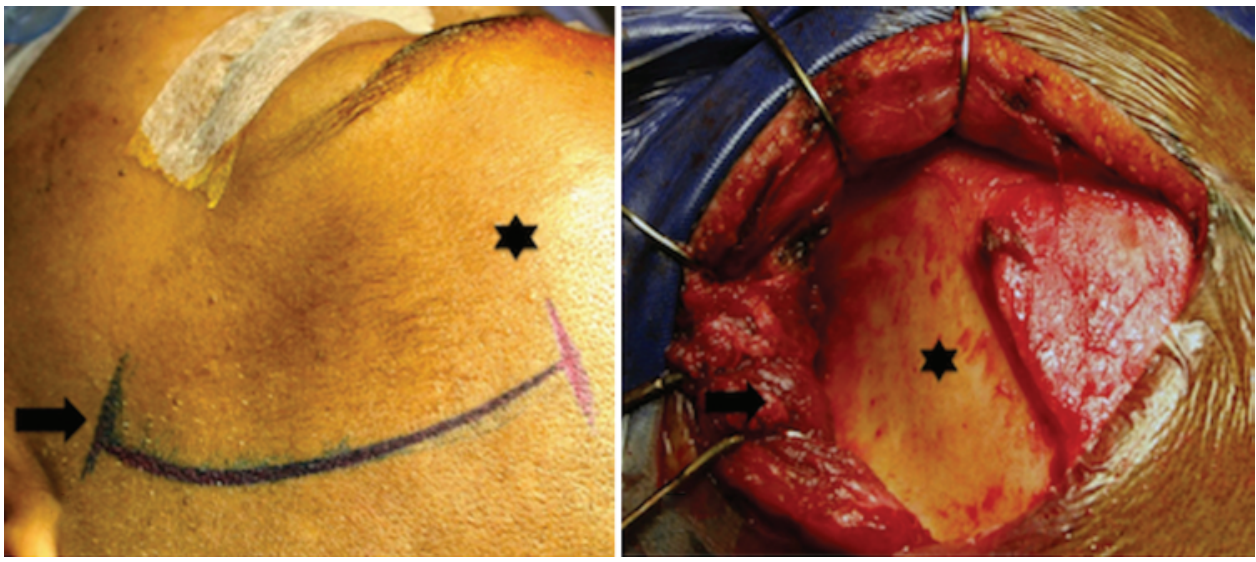

FIG. 1. Left: Preoperative planning. The scalp incision begins $1 \mathrm{~cm}$ above the base of the zygomatic arch at the anterior border of the hairline (arrow). It is extended cranially and curved gradually toward the ipsilateral midpupillary line (asterisk). Right: Exposure of the pterion (asterisk). The muscular flap is retracted caudally and posteriorly, subperiosteally (arrow). Figure is available in color online only.

such as cerebrospinal fluid leakage, postoperative ischemic lesions, hydrocephalus, and wound infection, were recorded as well.

\section{Quantitative Evaluation of Atrophy}

The degree of atrophy was measured with 3 methods using helical CT scans. On these scans we observed the percentage reduction in thickness of the temporal muscle, subcutaneous tissue, and skin (Method 1) and the percentage reduction in thickness of the isolated temporal muscle (Method 2). Measurements were made at the beginning of the sphenoid wing as it appeared on the CT scan. Additionally, the volume of the temporal muscle, subcutaneous tissue, and skin (Method 3) was calculated from the superior edge of the zygomatic arch to the superior temporal line using OsiriX software. Serial image measurements were calculated to approximate the volume of the temporal muscle. A region of interest (ROI) was drawn to outline the temporal muscle on each 2D slice of the series to create a 3D volume reconstruction of the temporal muscle in each patient. The individual ROIs were then grouped and locked as a single ROI to properly segment the muscle.

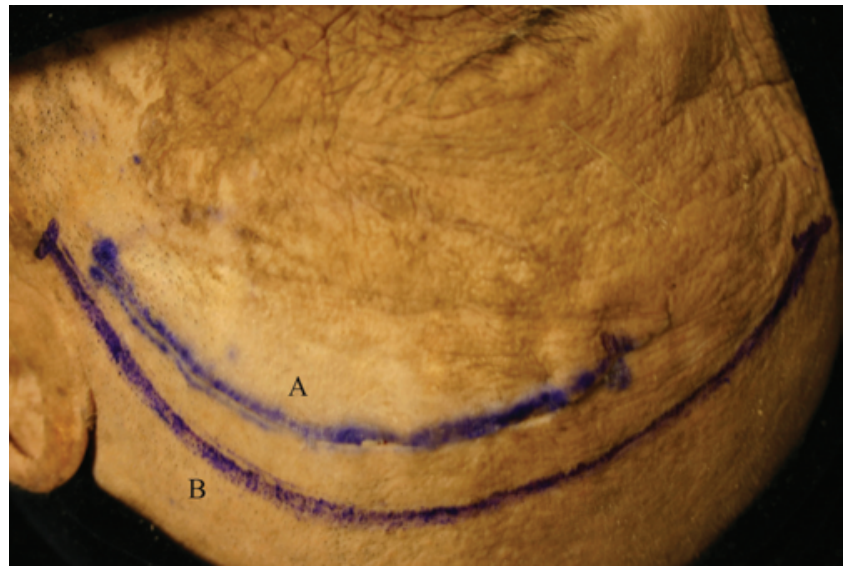

FIG. 2. Skin incision comparison between the MPT (A) and PT (B) approaches. Figure is available in color online only.
Finally, the software was used to create a 3D volume per patient. (Fig. 5)

\section{Aesthetic Results}

The aesthetic results were analyzed using 2 methods. In the first, the patients were shown a rule with a scale from 0 to 100, in which 0 meant the best result and 100 the worst result (Fig. 6). In the second method, photos were taken and shown to 2 independent observers. They classified aesthetic results as excellent, good, regular, or poor, according to a predetermined scale (Table 1).

\section{Statistical Analysis}

Our primary end point was satisfaction with the aesthetic results. Sample size was calculated on the premise that the aesthetic results of MPT craniotomy would be superior to those of the PT technique. A sample size of 48 was calculated ( $\alpha=0.05$ and $\beta=0.20$ ) based on the assumption that $75 \%$ of patients in the MPT group and $40 \%$ in the PT group would be satisfied with their cosmetic results. A paired Student t-test was used to compare the degree of atrophy on the nonoperated side of the temporal muscle with

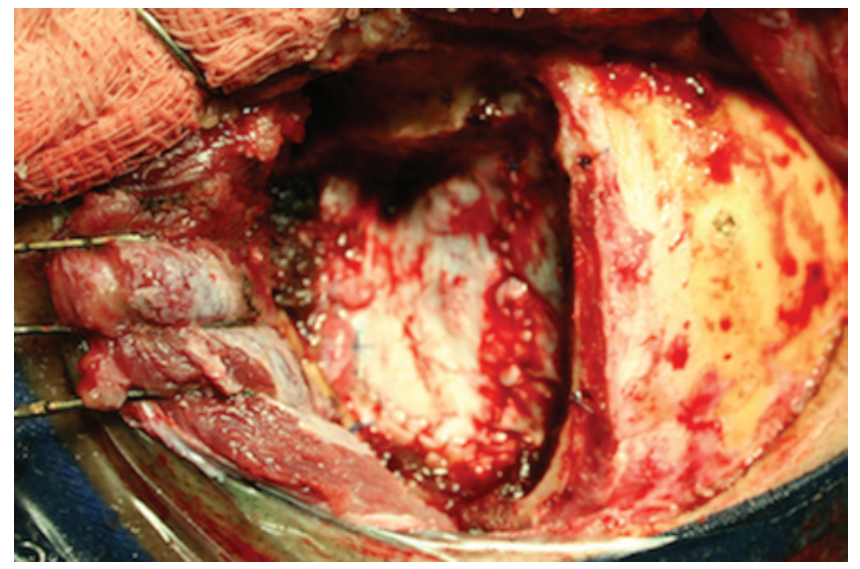

FIG. 3. The bone flap includes a minimal portion of the frontal and temporal bones. The entire area of the craniotomy is under the temporal muscle. Figure is available in color online only. 


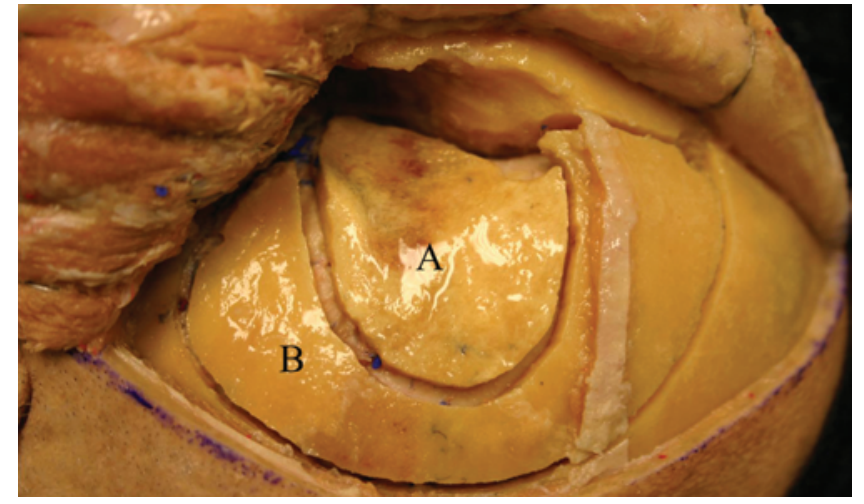

FIG. 4. Bone removal comparison: MPT (A) versus PT (B). Note how the bone to be removed is beyond the superior limits of the temporal muscle. Figure is available in color online only.

that on the operated side. For categorical data, a Fisher test and chi-square test with Yates correction were used. Differences were considered significant if the $p$ value was less than 0.05. Interobserver reliability was measured with the kappa coefficient, and high concordance was present when the results were greater than 0.7.

\section{Results}

This randomized prospective series consisted of 58 patients with aneurysm. Twenty-eight patients were treated with MPT craniotomy and 30 with the standard PT approach. There were no differences between the groups regarding age, sex, ethnic origin, alcohol consumption, smoking history, and other comorbidities (Table 2).

The admission variables, described as ruptured aneurysm, Hunt and Hess scale score, Fisher scale score, and hydrocephalus, were similar (Table 3 ). In both groups, the number of patients with ruptured aneurysms surgically treated in the acute phase $(<5$ days $)$ and aneurysm distribution along the anterior cerebral circulation were similar. Clinical results measured by the $\mathrm{mRS}$ were similar in both groups at the 6-month evaluation $(\mathrm{p}=0.99$; Table 4$)$.

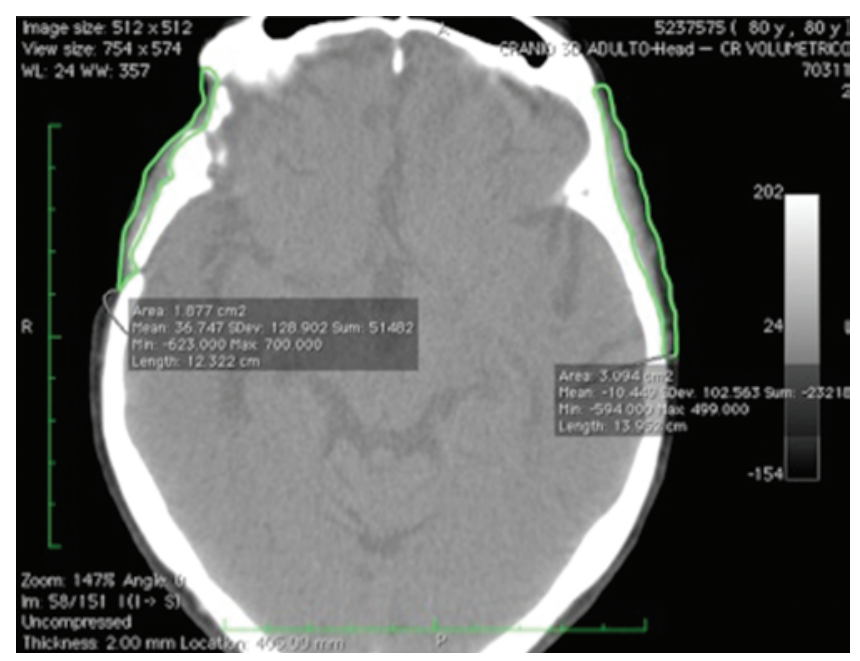

FIG. 5. Postoperative CT. An ROI (green line) was drawn to outline the temporal muscle on each 2D slice. Figure is available in color online only.

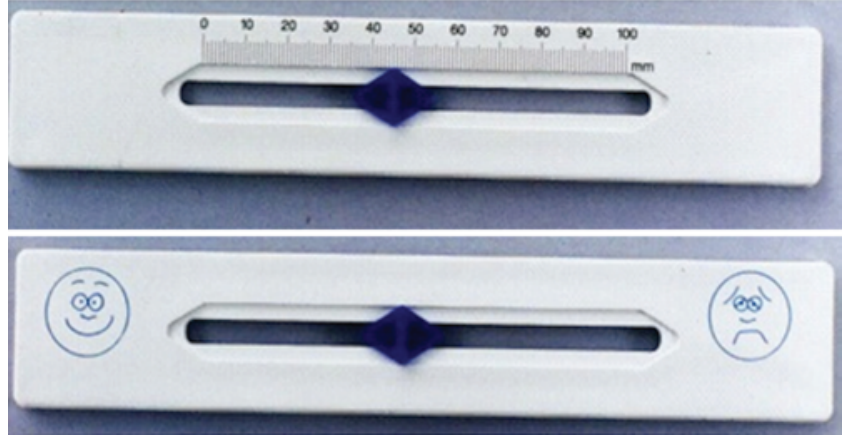

FIG. 6. To quantify the aesthetic results, patients were shown a rule with a scale from 0 to 100, in which 0 meant the best result and 100 the worst result. Figure is available in color online only.

Four patients in the MPT group and 5 in the PT group died $(\mathrm{p}=1.0)$. Intraoperative aneurysm rupture occurred in 4 patients (14\%) in the MPT group and $5(17 \%)$ in the PT group $(\mathrm{p}=1.0)$. Lamina terminalis opening was performed in 6 patients (21\%) in the MPT and $6(20 \%)$ in the PT groups $(\mathrm{p}=1.0)$. Postoperative hydrocephalus, frontal muscle paresis, cerebrospinal fluid leakage, and ischemic lesions due to vasospasm were similar in the 2 groups (Table 5).

Six months after hospital discharge, 19 patients (79\%) and 13 patients (52\%) in the MPT and PT groups, respectively, were satisfied with their cosmetic results $(p=0.07)$. The mean value observed on the aesthetic rule was 27 in the MPT group and 45.8 in the PT group $(p=0.03)$. When only patients classified as having an mRS score of 0 or 1 were considered, the mean scores on the aesthetic satisfaction rule were 25.2 and 39.4 in the MPT and PT groups, respectively ( $\mathrm{p}=0.11$; Table 6$)$. Two independent observers, a neurosurgeon and a plastic surgeon, analyzed the patients' photos, and the kappa coefficient for the aesthetic results was 0.73 . According to these observers, excellent and good results were observed in 21 patients $(87 \%)$ in the MPT group and $12(48 \%)$ in the PT group ( $\mathrm{p}=0.005$; Fig. 7).

The degrees of temporal muscle, subcutaneous tissue, and skin atrophy (Method 1) were $14.9 \%$ and $24.3 \%$ for the MPT and PT groups, respectively $(\mathrm{p}=0.01)$. Measuring the thickness of the temporal muscle (Method 2) revealed a $12.7 \%$ degree of atrophy for MPT and $22 \%$ for PT $(\mathrm{p}=0.005)$. The volumetric reductions (Method 3) were $14.6 \%$ and $24.4 \%$ in MPT and PT groups, respectively $(\mathrm{p}=0.001$; Table 7$)$.

\section{Discussion}

The fundamental objective of every intracranial aneurysm surgery is to isolate the aneurysm and eliminate the risk of rebleeding without compromising neurological

TABLE 1. Classification of aesthetic results

\begin{tabular}{ll}
\hline Result & \multicolumn{1}{c}{ Description } \\
\hline Excellent & No visible scar; no atrophy; no keloid \\
\hline Good & Partially visible scar; mild atrophy; no keloid \\
\hline Regular & Partially visible scar; moderate atrophy; visible keloid \\
\hline Poor & Totally visible scar; craniofacial deformity \\
\hline
\end{tabular}


TABLE 2. Summary of demographic data*

\begin{tabular}{lccc}
\hline \multicolumn{1}{c}{ Variable } & MPT Craniotomy & PT Craniotomy & p Value \\
\hline Sex & & & 0.78 \\
\hline M & 8 & 10 & \\
\hline F & 20 & 20 & \\
\hline Race & & & 0.30 \\
\hline White & 15 & 20 & \\
\hline Mixed race $\dagger$ & 9 & 6 & \\
\hline Black & 4 & 4 & \\
\hline Hypertension & 18 & 15 & 0.30 \\
\hline Mean age in yrs (range) & $50.3(35-67)$ & $51.1(25-79)$ & 0.78 \\
\hline Smoking history & 13 & 13 & 1.0 \\
\hline Alcohol comsumption & 5 & 4 & 0.72 \\
\hline
\end{tabular}

* Values are no. of patients unless otherwise indicated.

$\dagger$ Not white or black.

function. ${ }^{4}$ The history of intracranial surgery for aneurysms is not a long one. ${ }^{25}$ Norman Dott, who wrapped a ruptured aneurysm in 1933, performed the first direct operation on an intracranial aneurysm. Walter Dandy performed the first obliterative clipping of an aneurysm in 1938 .

A great improvement in surgical results occurred in 1975 when Yaşargil et al. proposed a craniotomy centered on the frontotemporal sylvian fissure with less exposure of the frontal and temporal lobes. ${ }^{28}$ Compared with other techniques, the approach described by Yaşargil et al. limited the extent of the craniotomy and added the removal of the lateral two-thirds of the lesser sphenoid wing, including the microsurgical removal and opening of the sylvian fissure and cistern, with the objective of reducing retraction of the frontal lobe. ${ }^{26-28}$ These technical innovations, the introduction of the surgical microscope, and the description of the microtechniques that are still in use today are responsible for the current surgical results. ${ }^{26-28}$

TABLE 3. Summary of admission variables

\begin{tabular}{lrrr}
\hline \multirow{2}{*}{ Variable } & \multicolumn{2}{c}{ No. of Patients } & \\
\cline { 2 - 3 } & MPT Craniotomy & PT Craniotomy & p Value \\
\hline Aneurysm rupture & & & 0.78 \\
\hline Yes & 19 & 21 & \\
\hline No & 9 & 9 & \\
\hline Hunt \& Hess grade & & & 0.98 \\
\hline I & 5 & 8 & \\
\hline II & 9 & 10 & \\
\hline III & 4 & 3 & \\
\hline IV & 1 & 0 & \\
\hline Fisher grade & & & \\
\hline 1 & 2 & 4 & \\
\hline 2 & 3 & 6 & \\
\hline 3 & 6 & 8 & \\
\hline 4 & 7 & 3 & \\
\hline Hydrocephalus & & & \\
\hline Yes & 7 & 6 & \\
\hline No & 21 & 24 & \\
\hline
\end{tabular}

TABLE 4. 6-month mRS scores*

\begin{tabular}{ccc}
\hline & \multicolumn{2}{c}{ No. of Patients } \\
\cline { 2 - 3 } mRS Score & MPT Craniotomy & PT Craniotomy \\
\hline 0 & 15 & 13 \\
\hline 1 & 7 & 8 \\
\hline 2 & 2 & 2 \\
\hline 3 & 0 & 1 \\
\hline 4 & 0 & 1 \\
\hline 5 & 0 & 0 \\
\hline
\end{tabular}

* Clinical results as measured by the $\mathrm{mRS}$ scale were similar in both groups $(p=0.99)$.

To maximize the PT exposure, the temporal muscle is usually completely dissected from the temporal fossa. However, such a maneuver presents some drawbacks, including functional and aesthetic complications. Researchers have recently demonstrated alterations in mandibular function, chronic pain, and alterations in the facial sensory components. Such outcomes are frequently associated with temporal atrophy and injury of the frontal branch of the facial nerve and trigeminal branches. ${ }^{1,3,8,11-13}$

The theoretical advantages of minimally invasive procedures are shorter surgical procedures and hospital stays, less operative trauma, reduced costs, less pain, and better cosmetic results compared with those following standard craniotomies. Accordingly, over the past 2 decades, the neurosurgical community has strived to balance the need to minimize tissue trauma, maximize anatomical exposure, and optimize surgical results. For these reasons, many surgical modifications have been added to the traditional PT craniotomy. ${ }^{13}$ Several different techniques have been described; however, the refinements fail to provide a

TABLE 5. Summary of operative complications and mortality

\begin{tabular}{lrrr}
\hline & \multicolumn{2}{c}{ No. of Patients } & \\
\cline { 2 - 3 } Parameter & MPT Craniotomy & PT Craniotomy & p Value \\
\hline Postop hematoma & & 2 & 1.0 \\
\hline Yes & 26 & 28 & \\
\hline No & & & 1.0 \\
\hline CSF leakege & 0 & 0 & \\
\hline Yes & 28 & 30 & \\
\hline No & & & 0.74 \\
\hline Postop ischemic lesions & 6 & 5 & \\
\hline Yes & 22 & 25 & \\
\hline No & & & 1.0 \\
\hline Hydrocephalus & 2 & 2 & \\
\hline Yes & 26 & 28 & \\
\hline No & & & 1.0 \\
\hline Wound infection & 2 & 3 & \\
\hline Yes & 26 & 27 & \\
\hline No & & & \\
\hline Death & 4 & 25 & \\
\hline Yes & 24 & & \\
\hline No & & & \\
\hline
\end{tabular}


TABLE 6. Summary of aesthetic results

\begin{tabular}{|c|c|c|c|}
\hline Parameter & $\begin{array}{c}\text { MPT } \\
\text { Craniotomy }\end{array}$ & $\begin{array}{c}\text { PT } \\
\text { Craniotomy }\end{array}$ & $\mathrm{p}$ Value \\
\hline No. of patients & & & 0.13 \\
\hline Aesthetic rule score $>50$ & $5(21 \%)$ & $12(48 \%)$ & \\
\hline Aesthetic rule score $<50$ & $19(79 \%)$ & $13(52 \%)$ & \\
\hline Mean aesthetic rule score overall & 27.0 & 45.8 & 0.03 \\
\hline $\begin{array}{l}\text { Mean aesthetic rule score among } \\
\text { patients } w / \text { mRS Score } 0 \text { or } 1\end{array}$ & 25.2 & 39.4 & 0.11 \\
\hline No. of patients satisfied overall & & & 0.07 \\
\hline Yes & $19(79 \%)$ & $13(52 \%)$ & \\
\hline No & $5(21 \%)$ & $12(48 \%)$ & \\
\hline $\begin{array}{l}\text { No. of patients satisfied among } \\
\text { those } \mathrm{w} / \mathrm{mRS} \text { Score } 0 \text { or } 1\end{array}$ & & & 0.04 \\
\hline Yes & $19(86 \%)$ & $12(57 \%)$ & \\
\hline No & $3(14 \%)$ & $9(43 \%)$ & \\
\hline
\end{tabular}

comparable microsurgical exposure, and some do not reduce the extent of dissection of the temporal muscle. ${ }^{5,10,14,16}$ The surgical literature has very few studies comparing operative techniques. The preference and experience of the surgeon, rather than well-designed randomized prospective studies, usually dictate the selection of approaches. To the best of our knowledge, this is the first prospective randomized study comparing 2 surgical techniques.

\section{Minipterional Craniotomy}

Decreasing the size of the craniotomy may lead to restricted maneuverability and narrowing of the visual field, which can compromise the safety of the technique. $.18,20$ In other words, the 2 main concerns about the minimally invasive surgery are, first, whether the surgical field we attain is sufficient to deal with an intracranial aneurysm, and second, what is the possibility of resolving an intraoperative aneurysm rupture. In the MPT technique, the pterion is a landmark for determining the posterior and distal limits of the craniotomy. ${ }^{10,11}$ Exposure and dissection of only the segment proximal to the pterion optimize exposure
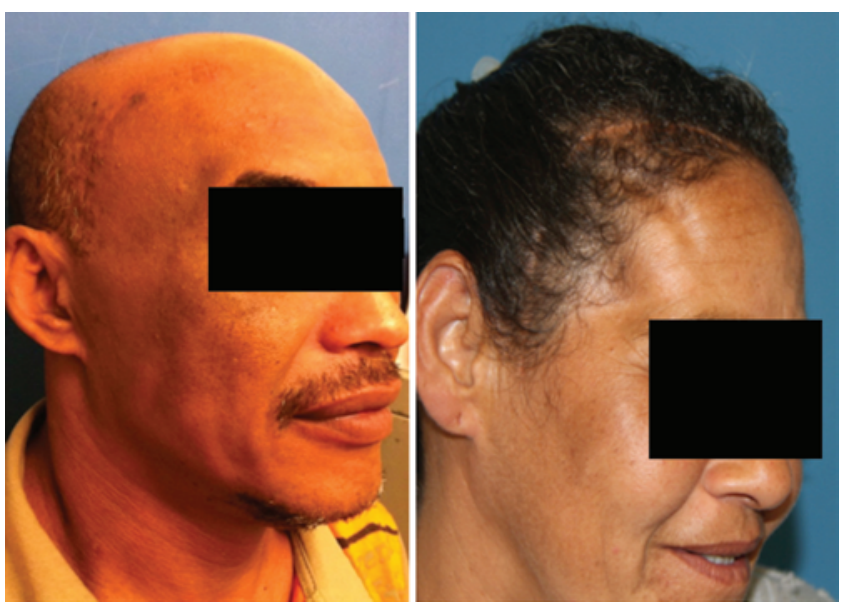

FIG. 7. Left: Aesthetic result of MPT craniotomy. Right: Aesthetic result of PT craniotomy. Figure is available in color online only.
TABLE 7. Degree of temporal muscle atrophy

\begin{tabular}{cccc}
\hline Measurement & $\begin{array}{c}\text { MPT } \\
\text { Craniotomy }\end{array}$ & $\begin{array}{c}\text { PT } \\
\text { Craniotomy }\end{array}$ & p Value \\
\hline $\begin{array}{c}\text { Global reduction (muscle, sub- } \\
\text { cutaneous tissue, \& skin) }\end{array}$ & $14.9 \%$ & $24.3 \%$ & 0.01 \\
\hline $\begin{array}{c}\text { Reduction in temporal muscle } \\
\text { thickness }\end{array}$ & $12.7 \%$ & $22.0 \%$ & 0.005 \\
\hline $\begin{array}{c}\text { Volumetric reduction (muscle, } \\
\text { subcutaneous tissue, skin) }\end{array}$ & $14.6 \%$ & $24.4 \%$ & 0.001 \\
\hline
\end{tabular}

of the transsylvian anatomy. Thus, the 2 main features of the standard PT technique-the extensive drilling of the lateral aspect of the sphenoid wing and the wide opening of the sylvian fissure-are also possible in similar extension when performing the MPT craniotomy. Therefore, the transsylvian surgical exposures are quite similar., ${ }^{10,11}$

\section{Clinical Outcome}

Although this series is small and many factors could influence outcomes, our clinical results, as measured by the mRS, were similar in both groups at the 6-month evaluation. Even in cases in which intraoperative rupture of the aneurysm occurred, surgery was still successfully finished without the need to change the MPT approach to a standard PT craniotomy. There also were no differences between the 2 craniotomies with regard to postsurgical complications. The results demonstrate that the MPT craniotomy is as safe and effective as the PT technique. It is as versatile as the PT approach and adds no further morbidity.

The number of patients in this study was not large enough to demonstrate more subtle differences. However, groups were very homogeneous considering the main factors that affect prognosis, including age, Hunt and Hess grade, and Fisher grade, so the influences of those factors were similar in both groups.

\section{Aesthetic Results}

Historically, as surgical outcomes improve, increasing focus is placed on alternate measures of success. One of these is the unacceptably common development of temporal muscle atrophy and hollowing of the temporal area. ${ }^{1,10,11}$ The temporal muscle can sustain injury leading to atrophy by denervation of the muscle, damage to its vascular supply, or direct muscle fiber injury (Fig. 3).,10,11 A high incidence of temporal hollowing and cosmetic dissatisfaction among patients has led to several proposed methods of muscle preservation. $1,2,3,6,11,12,15,19,23,24,29$

Oikawa et al. published the most often referenced modification. ${ }^{21}$ They reported cosmetically satisfactory outcomes in 100 patients, which were obtained by avoiding the use of electrocautery and dissecting the temporal muscle in a retrograde fashion. However, the results are not specified and were not compared with those of any control group..$^{21}$ In our study, satisfaction with aesthetic results was more commonly described in patients who underwent the MPT technique. The mean observed on the aesthetic rule was different between the groups, with results favorable 
toward MPT craniotomy $(\mathrm{p}=0.03)$. To reduce bias in the evaluation of the cosmetic result, 2 independent observers analyzed the patients' photos, and the kappa coefficient for the aesthetic results was $0.73 .{ }^{17}$ This is the first study in which the aesthetic results in patients treated via PT craniotomy have been compared with those following a minimally invasive technique for intracranial aneurysms.

\section{Radiological Atrophy Measurements}

In addition to assessing patient satisfaction, several authors have attempted to measure the volumetric size of the temporal muscle. De Andrade et al. compared 2 technical variations of fronto-temporo-sphenoidal craniotomy, the myocutaneous and interfascial dissections. ${ }^{8}$ They evaluated the asymmetry of the temporal muscle by measuring a bitemporal diameter, and according to them, there was a severe progressive pattern of temporal muscle atrophy in both groups. The severity of this atrophy was worse in the interfascial dissection than in the myocutaneous dissection group, especially at the 6-month evaluation. ${ }^{8} \mathrm{How}-$ ever, this method of analysis assesses only one point of the muscle and is prone to greater error if the muscle is attached imperfectly.

Hwang et al. did not find any differences regarding volumetry of the temporal muscle when comparing patients treated with and without electrocautery. ${ }^{15}$ In our work, this device was not included as a variable that could influence the results. Park and Hamm quantified temporal hollowing by measuring the thickness of the muscle, but again this approach reflects only a single $2 \mathrm{D}$ measure and may be disposed to error based on the temporal muscle reattachment. ${ }^{22}$ Our 3 different methods of measuring the degree of temporal muscle atrophy, including volumetric analysis that reflects the entire temporal muscle, minimize error in measurements arising from temporal muscle re-suture.

The contralateral side was used as the control to minimize errors arising from radiological acquisition, as the images have been obtained in different planes. Thus, volumetric analysis of the contralateral side could be obtained in the same plane as the operated side, allowing for a more direct comparison. Additionally, as the temporal muscle is bilateral and symmetric, we should not have expected significant asymmetry between the sides, and we could not find any paper in the literature describing a lack of symmetry in the action of the temporal muscle.

It should be emphasized that there are many factors contributing to these results, especially the surgeon's familiarity with the technique. However, the modifications of the MPT over the PT craniotomy are simple and can be done easily by all neurosurgeons involved in vascular neurosurgery.

\section{Conclusions}

In this study no differences in clinical outcomes between the MPT and PT techniques were observed. Additionally, MPT craniotomy provides better cosmetic results with less facial contour deformity. The MPT approach can be considered a safe and effective alternative for operating on ruptured and unruptured anterior circulation aneurysms and can be used instead of the PT approach, since it provides additional advantages, such as superior aesthetic results.

\section{References}

1. Ammirati M, Spallone A, Ma J, Cheatham M, Becker D: Preservation of the temporal branch of the facial nerve in pterional-transzygomatic craniotomy. Acta Neurochir (Wien) 128:163-165, 1994

2. Badie B: Cosmetic reconstruction of temporal defect following pterional [corrected] craniotomy. Surg Neurol 45:383384, 1996

3. Barone CM, Jimenez DF, Boschert MT: Temporalis muscle resuspension using titanium miniplates and screws: technical note. Neurosurgery 48:450-451, 2001

4. Bederson JB, Connolly ES Jr, Batjer HH, Dacey RG, Dion JE, Diringer MN, et al: Guidelines for the management of aneurysmal subarachnoid hemorrhage: a statement for healthcare professionals from a special writing group of the Stroke Council, American Heart Association. Stroke 40:994-1025, 2009

5. Chehrazi BB: A temporal transsylvian approach to anterior circulation aneurysms. Neurosurgery 30:957-961, 1992

6. Coscarella E, Vishteh AG, Spetzler RF, Seoane E, Zabramski JM: Subfascial and submuscular methods of temporal muscle dissection and their relationship to the frontal branch of the facial nerve. Technical note. J Neurosurg 92:877-880, 2000

7. Dandy WE (ed): The Brain. Hagerstown, MD: WF Prior, 1966

8. de Andrade FC Jr, de Andrade FC, de Araujo Filho CM, Filho JC: Dysfuntion of the temporalis muscle after pterional craniotomy for intracranial aneurysms. Comparative, prospective and randomized study of one flap versus two flaps dieresis. Arq Neuropsiquiatr 56:200-205, 1998

9. Ezer H, Banerjee AD, Shorter C, Nanda A: The "agnes fast" craniotomy: the modified pterional (osteoplastic) craniotomy. Skull Base 21:159-164, 2011

10. Figueiredo EG: Descrição Técnica e Avaliação Anatômica da Craniotomia Minipterional [dissertation]. São Paulo: Faculdade de Medicina, Universidade de São Paulo, 2008

11. Figueiredo EG, Deshmukh P, Nakaji P, Crusius MU, Crawford N, Spetzler RF, et al: The minipterional craniotomy: technical description and anatomic assessment. Neurosurgery 61 (5 Suppl 2):256-265, 2007

12. Figueiredo EG, Deshmukh P, Zabramski JM, Preul MC, Crawford NR, Spetzler RF: The pterional-transsylvian approach: an analytical study. Neurosurgery 59 (4 Suppl 2):ONS263-ONS269, 2006

13. Figueiredo EG, Oliveira AMP, Plese JP, Teixeira MJ: Perspective of the frontolateral craniotomies. Arq Neuropsiquiatr 68:430-432, 2010

14. Harland SP, Hussein A, Gullan RW: Modification of the standard pterional approach for aneurysms of the anterior circle of Willis. Br J Neurosurg 10:149-153, 1996

15. Hwang SW, Abozed MM, Antoniou AJ, Malek AM, Heilman $\mathrm{CB}$ : Postoperative temporalis muscle atrophy and the use of electrocautery: a volumetric MRI comparison. Skull Base 20:321-326, 2010

16. Kim E, Delashaw JB Jr: Osteoplastic pterional craniotomy revisited. Neurosurgery 68 (1 Suppl Operative): 125-129, 2011

17. Landis JR, Koch GG: The measurement of observer agreement for categorical data. Biometrics 33:159-174, 1977

18. McLaughlin N, Cutler A, Martin NA: Technical nuances of temporal muscle dissection and reconstruction for the pterional keyhole craniotomy. J Neurosurg 118:309-314, 2013

19. Miyazawa T: Less invasive reconstruction of the temporalis muscle for pterional craniotomy: modified procedures. Surg Neurol 50:347-351, 1998 
20. Nathal E, Gomez-Amador JL: Anatomic and surgical basis of the sphenoid ridge keyhole approach for cerebral aneurysms. Neurosurgery 56 (1 Suppl):178-185, 2005

21. Oikawa S, Mizuno M, Muraoka S, Kobayashi S: Retrograde dissection of the temporalis muscle preventing muscle atrophy for pterional craniotomy. Technical note. J Neurosurg 84:297-299, 1996

22. Park J, Hamm IS: Cortical osteotomy technique for mobilizing the temporal muscle in pterional craniotomies. Technical note. J Neurosurg 102:174-178, 2005

23. Schlitt M, Quindlen EA: Osteoplastic pterional craniotomy. South Med J 82:592-595, 1989

24. Spetzler RF, Lee KS: Reconstruction of the temporalis muscle for the pterional craniotomy. Technical note. J Neurosurg 73:636-637, 1990

25. Tan TC, Black PM: Sir Victor Horsley (1857-1916): pioneer of neurological surgery. Neurosurgery 50:607-612, 2002

26. Vishteh AG, Marciano FF, David CA, Baskin JJ, Spetzler RF: The pterional approach. Oper Tech Neurosurg 1:39-49, 1998

27. Yaşargil MG, Antic J, Laciga R, Jain KK, Hodosh RM, Smith RD: Microsurgical pterional approach to aneurysms of the basilar bifurcation. Surg Neurol 6:83-91, 1976
28. Yaşargil MG, Fox JL: The microsurgical approach to intracranial aneurysms. Surg Neurol 3:7-14, 1975

29. Zager EL, Del Vecchio DA, Bartlett SP: Temporal muscle microfixation in pterional craniotomies. Technical note. J Neurosurg 79:946-947, 1993

\section{Author Contributions}

Conception and design: Welling, Figueiredo, Wen. Acquisition of data: Welling. Analysis and interpretation of data: Welling, Figueiredo, Wen, Gomes, Bor-Seng-Shu, Jacobsen Teixeira. Drafting the article: all authors. Critically revising the article: all authors. Reviewed submitted version of manuscript: all authors. Approved the final version of the manuscript on behalf of all authors: Welling. Statistical analysis: Welling. Study supervision: Jacobsen Teixeira.

\section{Correspondence}

Leonardo C. Welling, Rua Antonio Moro, 45 Jardim América, Ponta Grossa/Paraná 84050-440, Brazil. email: leonardowelling@ yahoo.com.br. 